\title{
IMPLANTAÇÃO DE UM MODELO DE GESTÃO DE SEGURANÇA NA LOGISTICA DE AÇOS LONGOS DA CSN *
}

\section{Resumo}

Fabíola Freitas de Miranda ${ }^{1}$ Wellington Cesar de Paula ${ }^{2}$ Luiz Carlos da Costa ${ }^{3}$

Marcus Vinícius Damacena da Silva ${ }^{4}$ João Mário Lourenço Filho 5

A boa gestão das rotinas da Segurança no Trabalho é fundamental para apoiar um resultado positivo em vários aspectos dentro de uma operação de grande porte, como a da CSN. O colaborador é o bem mais importante de uma empresa e para garantir a satisfação e a qualidade de vida do mesmo é essencial que haja um ambiente de trabalho seguro e confiável. O zero acidente com pessoas é uma busca constante e com a consolidação de diversas ações de forma preventiva foi possível alcançar as metas propostas. Com o início das atividades de produção da fábrica de Aços Longos da CSN, houve a necessidade estruturar todas as atividades da equipe de logística, área responsável pelas atividades de abastecimento, logística interna e escoamento da planta, de forma a garantir que os funcionários estivessem envolvidos com as demandas geradas pela organização. Para isso, foi elaborado plano de trabalho com objetivos claros ligados a gestão de segurança.

Palavras-chave: Segurança no trabalho; Logística; Ação preventiva.

\section{IMPLEMENTATION OF SECURITY MANAGEMENT IN CSN LONG STEEL} LOGISTICS

\section{Abstract}

The good management of the routines of the Work Safety is essential to support a positive outcome in several aspects in large operation, as the one of CSN. The employee is the most important good of the company and to guarantee his or her satisfaction and life quality it is essential that there is a reliable and safe workplace. The Zero Accident with people is a constant effort and with the consolidation of several actions of the preventive ways it was possible to attain the proposed goals. With the start of the activities of CSN Long Steel Factory Production, there was the necessity to organize all the activities of the logistics team, the area in charge of the inbound activities, internal logistics e outbound of the factory, in order to guarantee that the employees could be involved with the demands generated by the organization. To that, a work plan was developed with clear objectives linked to the security management.

Keywords: Work Safety, Logistics, Preventive Action.

1 Administração de Empresas, Administrador, Analista de Logística, Gerência de Logística de Aços Longos, Companhia Siderúrgica Nacional. Via Sérgio Braga, no 272 - CEP 27260-390 - Ponte Alta, Volta Redonda, RJ, Brasil.

2 Tecnologia em Logística, Tecnólogo em Logística, Supervisor de Logística, Gerência de Logística de Aços Longos, Companhia Siderúrgica Nacional. Via Sérgio Braga, oㅡ 272 - CEP 27260-390 Ponte Alta, Volta Redonda, RJ, Brasil.

3 Administração de Empresas, Administrador, Especialista em Logística, Gerência de Logística de Aços Longos, Companhia Siderúrgica Nacional. Via Sérgio Braga, no 272 - CEP 27260-390 Ponte Alta, Volta Redonda, RJ, Brasil.

4 Administração de Empresas, Administrador, Gerente de Logística, Gerência de Logística de Aços Longos, Companhia Siderúrgica Nacional. Via Sérgio Braga, nº 272 - CEP 27260-390 - Ponte Alta, Volta Redonda, RJ, Brasil.

5 Engenharia Mecânica, Engenheiro, Diretor Operacional de Logística, Diretoria Operacional de Logística, Companhia Siderúrgica Nacional. Av. Faria Lima no 3400 - CEP 04538-132 - Itaim Bibi, SP, Brasil. 


\section{INTRODUÇÃO}

A CSN possui diversos negócios de atuação e há 4 anos atua no negócio de Aços Longos. Sua única fábrica no Brasil desse novo negócio está situada em Volta Redonda/RJ, dentro da Usina Presidente Vargas com capacidade produtiva de 500 mil toneladas/ano. Suas principais matérias primas para o processo de produção são sucata e ferro gusa, adquiridos de fornecedores externos.

A sucata é responsável por $68 \%$ da composição do aço líquido e é recebida na planta através de caminhões carregados, em sua maioria, no estado de São Paulo. Os outros 30\% da composição do aço líquido, o ferro gusa, é proveniente do estado de Minas Gerais e é recebido na planta por vagões. Ambas as matérias-primas são descarregadas num pátio específico destinado a este fim e levadas para abastecimento da Aciaria por vagões de movimentação interna da CSN.

À sucata e ao ferro gusa são acrescidos outros elementos que serão transformados no tarugo, matéria prima para a Laminação.

No forno de reaquecimento, os tarugos são reaquecidos para que sejam laminados em diferentes bitolas em formatos de reto ou rolo (Figura1).

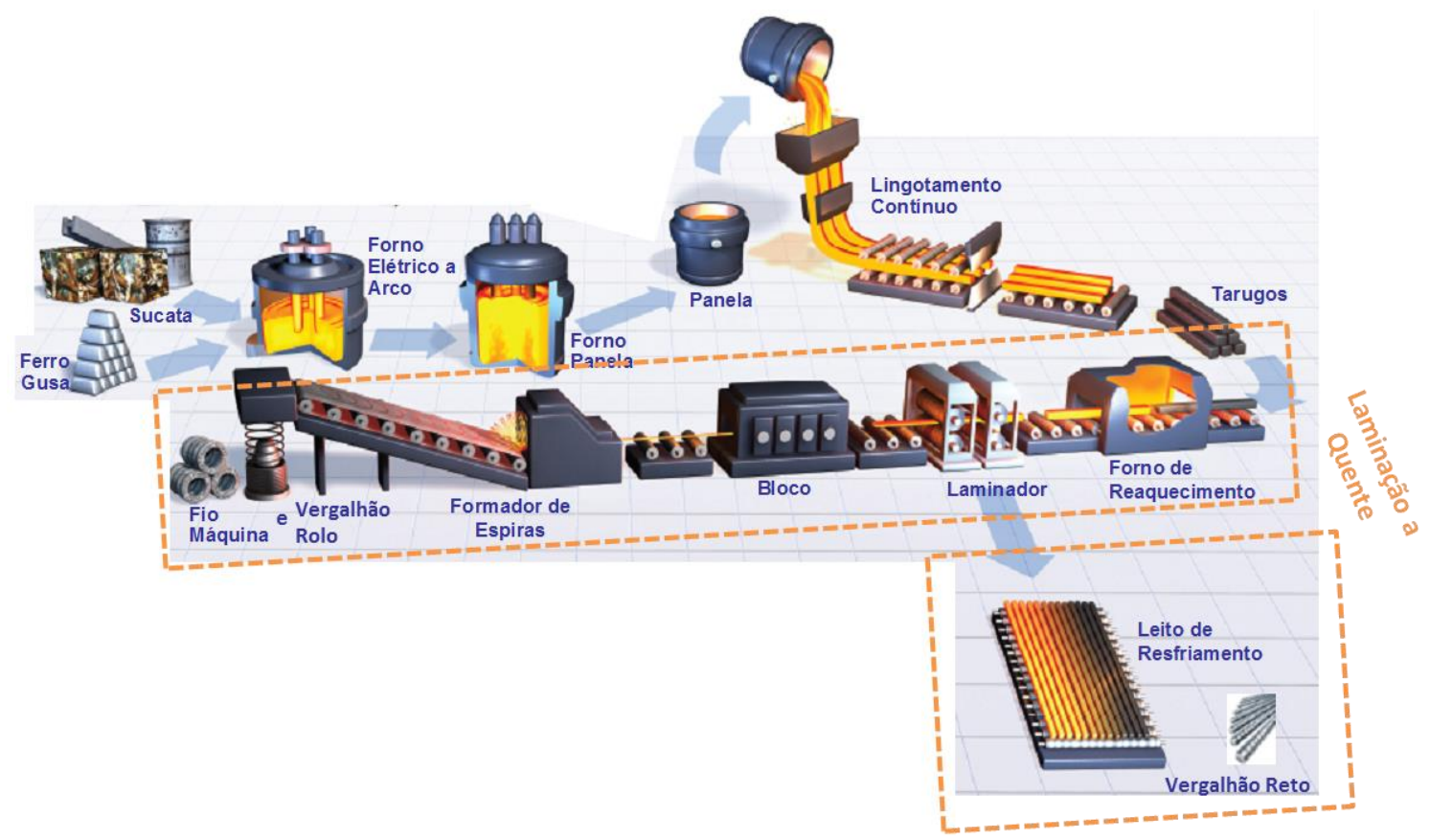

Figura 1. Processo de fabricação de Aços Longos

Após a conclusão do processo de Laminação, os materiais são disponibilizados para a Logística.

Fica a cargo da Logística as atividades de abastecimento da linha de produção, retirada de produção, movimentação e armazenamento de material (Figura 2) e carregamento de carretas e vagões. (Figura 3). 


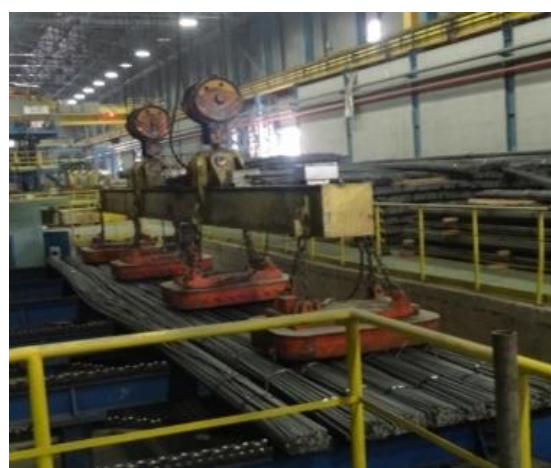

Figura 2. Movimentação

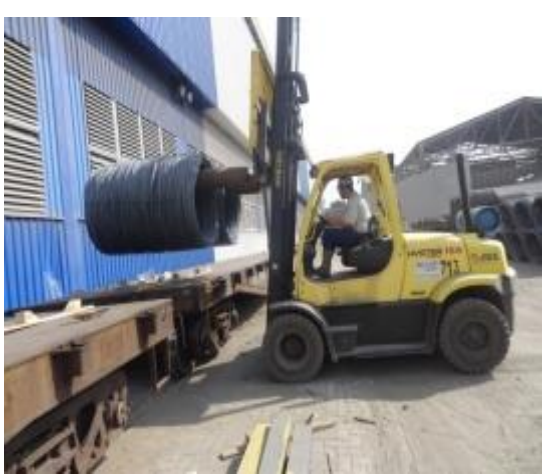

Figura3. Carregamento

Toda essa movimentação gera uma grande interface homem-máquina e produtos, criando situações de risco potencial para equipe de logística e também para colaboradores de outras áreas.

Com o objetivo de mitigar esses riscos em que os funcionários estão constantemente expostos na área, foi desenvolvido um modelo de gestão de segurança com foco na prevenção.

\section{MATERIAIS E MÉTODOS}

Este trabalho é resultado de reuniões realizadas ao longo do ano de 2012 e 2016, onde foram discutidos conceitos, ferramentas, dados, ideias e ações com participação do setor comercial e logístico do negócio.

A metodologia adotada foi o PDCA (Figura 4), disseminada por William Edwards Deming desde a década de 50, vêm sendo reconhecida por sua importância para melhoria dos processos. No Brasil, seu propagador foi Vicente Falconi que o adaptou e o descreve como "um método de gestão e o caminho para atingir metas" ou ainda como "um caminho para atingir metas".

No PDCA todo o processo é constituído por atividades que devem ser planejadas e recorrentes, sem que tenham um fim determinado conforme figura abaixo.

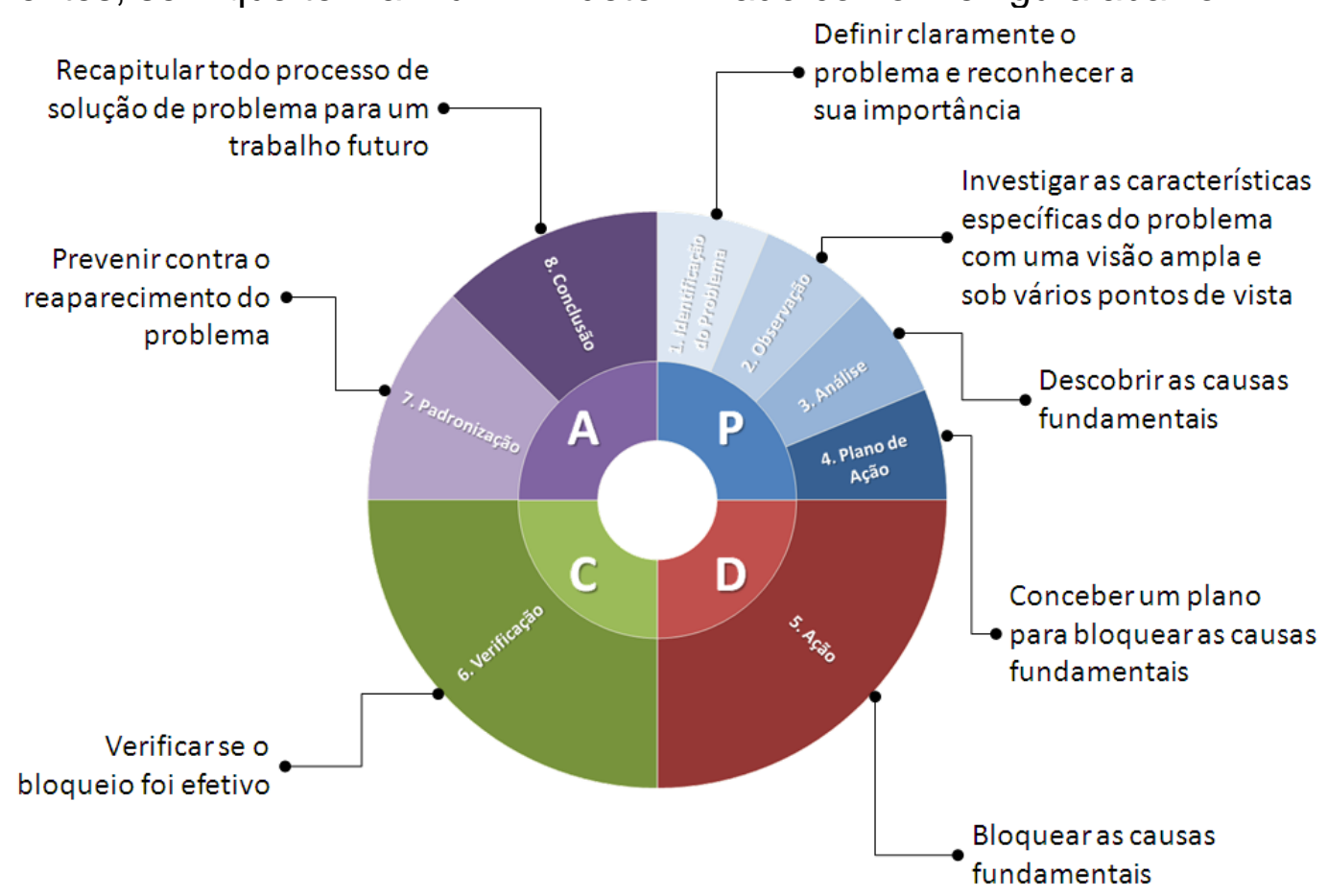

Figura 4. Ciclo PDCA 


\subsection{Segurança}

Em 2012, para compor a Gerência de Logística de Aços Longos, foi iniciada a contratação da equipe operacional e com eles, surgiu as primeiras demandas relacionadas a desenvolvimento de procedimentos, capacitação da equipe e aplicação de ferramentas para diagnóstico preventivo.

Baseada nas metas corporativas relacionadas a Taxa de Frequência, Taxa de Gravidade e Número de Acidentes, foi desenvolvida ações e metas para a área de logística.

Segundo Campos (2012 apud MEARNS; WHITAKER; FLIN, 2003), estudos evidenciam que uma cultura de segurança bem estabelecida é fundamental para o sucesso e o bom desempenho do Sistema de Gestão de Segurança do Trabalho, pois é na existência de uma cultura de segurança que as atitudes e o comportamento dos indivíduos relativo a segurança se desenvolvem.

\subsection{Definição e cronograma de implantação das ferramentas}

Dentre diversas ferramentas e ações que apoiam preventivamente a segurança do trabalho, foi definido junto com o SESMT - Serviço Especializado em Engenharia de Segurança e Medicina do Trabalho da CSN algumas que seriam implantadas para sustentar o sistema de gestão da segurança da gerência de Logística de Aços Longos:

- Criação e treinamento de procedimentos de cada atividade;

- Método para relato e tratamento de anomalias;

- Fórum para tratar assuntos de SST - Saúde e Segurança do Trabalho;

- Análise de risco;

- Observação comportamental.

Após essa definição, foi criado um calendário os prazos previstos para implantação de cada ferramenta (Figura 5). Houve divulgação desse cronograma para equipe garantindo o envolvimento e comprometimento de todos. 


\begin{tabular}{|c|c|c|}
\hline Atividades & Responsável & Quando \\
\hline 1. Elaboração de procedimentos & Supervisor & 2013 \\
\hline 1.1. Levantar atividades rotineiras & Supervisor & $31 / 03 / 2013$ \\
\hline 1.2. Levantar imagens e fotos das áreas & Supervisor & $30 / 04 / 2013$ \\
\hline 1.3. Desenvolver procedimentos & Supervisor & $30 / 06 / 2013$ \\
\hline 2. Treinamento dos procedimentos & Supervisor & 2013 \\
\hline 2.1. Desenvolver material para treinamento & Supervisor & $25 / 08 / 2013$ \\
\hline 2.2. Agendar sala e convocar participantes & Supervisor & $31 / 08 / 2013$ \\
\hline 2.3. Realizar treinamento & Supervisor & $31 / 10 / 2013$ \\
\hline 3. Implantar relatos de anomalias & Supervisor & 2014 \\
\hline 3.1. Treinar identificação de anomalias e como relatar & Supervisor & $31 / 01 / 2014$ \\
\hline 3.2. Disponibilizar ferramenta para registro de relatos & Facilitador & $05 / 02 / 2014$ \\
\hline 3.3. Criar controle e plano de ação & Facilitador & $20 / 02 / 2014$ \\
\hline 4. Criar rotina de reunião de segurança & Gerente & 2014 \\
\hline 4.1. Definir calendário de reuniões de segurança & Gerente & $31 / 01 / 2014$ \\
\hline 4.2. Garantir participação e evidências das reuniões & Facilitador & $10 / 02 / 2014$ \\
\hline 4.3. Criar controle e plano de ação & Facilitador & $28 / 02 / 2014$ \\
\hline 5. Criar cronograma de mapeamento de risco & Supervisor & 2015 \\
\hline 5.1. Definir atividades prioritárias para o mapeamento & Supervisor & $31 / 03 / 2015$ \\
\hline 5.2. Criar controle e plano de ação & Facilitador & $30 / 04 / 2015$ \\
\hline 6. Implantar rotina de observação comportamental & Gerente & 2016 \\
\hline 6.1. Definir executores da observação comportamental & Gerente & $28 / 02 / 2016$ \\
\hline 6.2. Treinar em observação comportamental & Supervisor & $30 / 04 / 2016$ \\
\hline 6.3. Criar controle e plano de ação & Facilitador & $10 / 05 / 2016$ \\
\hline
\end{tabular}

Figura 5. Cronograma de implantação

\subsection{Desenvolvimento da Gestão de Segurança}

Juliana Bley diz "Ensinar alguém a trabalhar com consciência de segurança passa, necessariamente, por ensinar esse alguém a conhecer criticamente sua realidade, a fazer escolhas com relação a elas, considerando as consequências para si e para aqueles que o cercam. Assim posto, o processo de conscientização e educação com foco na prevenção não pode ficar restrito ao nível da obediência e do controle. "

\subsubsection{Procedimentos}

O detalhamento de cada atividade a ser executada pela equipe foi mapeado, fotografado e inserida em um procedimento com seu passo a passo. Também foram destacados os pontos críticos de segurança.

Todos os colaboradores da Logística foram treinados em sala de aula nos procedimentos e posteriormente foram realizados os treinamentos on-the-job.

O controle dos procedimentos e dos treinamentos são realizados em um software utilizado pela empresa.

2.3.2 Relato de anomalias

Identificar e mapear desvios estruturais no ambiente de trabalho é uma forma preventiva de sanar possíveis acidentes. Com isso, implantamos a ferramenta de comunicação de anomalias junto a equipe operacional. Equipe operacional é a mais indicada para identificar as anomalias.

Todos foram capacitados e o tratamento das anomalias tratados através de plano de ação.

2.3.3 Análise dos riscos

Para garantir que todos os riscos estejam sendo realmente identificadas e cobertos dentro do procedimento, foi criado cronograma para análise de todas as 
atividades realizadas pela equipe de Logística de Aços Longos. Foi mapeado do mais crítico para o menos crítico, para que o Supervisor e o Técnico de Segurança da área fossem analisando atividade por atividade e avaliando os riscos inerentes a cada operação. Após cada avaliação, os dados coletados são lançados em uma planilha que calcula o resultado com base na prioridade de e $\mathrm{n}$ o de pessoas expostas ao risco.

2.3.4 Observação Comportamental

Atividade de inspeção no local de trabalho com foco em identificar possíveis desvios de comportamento do colaborador e como ele interage com o ambiente naquele momento. É gerado relatório com os desvios encontrados para tratativa.

2.3.5 Reunião

Criar fórum semanal com foco no assunto de Segurança para garantir que todas as ferramentas estão sendo verificadas e suas demandas sendo geridas. Todas as demandas levantadas são registras em plano de ação e acompanhado semanalmente.

\section{RESULTADOS E DISCUSSÃO}

Com a implantação da gestão de segurança foi possível alcançar um resultado positivo, trazendo para área um ganho muito significativo. Foi completado no mês de março de 2017 cinco anos sem acidentes com pessoas, englobando nessa conquista tanto funcionário próprio quanto terceiros.

A aplicação das diversas ferramentas na área contribuiu para criação de novos procedimentos e aperfeiçoamento dos demais. Os procedimentos ficaram mais visuais e com fotos, contribuindo para o melhor entendimento (Figura 6). As revisões trouxeram mais demandas de treinamentos trazendo evolução e mais conhecimentos para equipe. (Tabela 1)
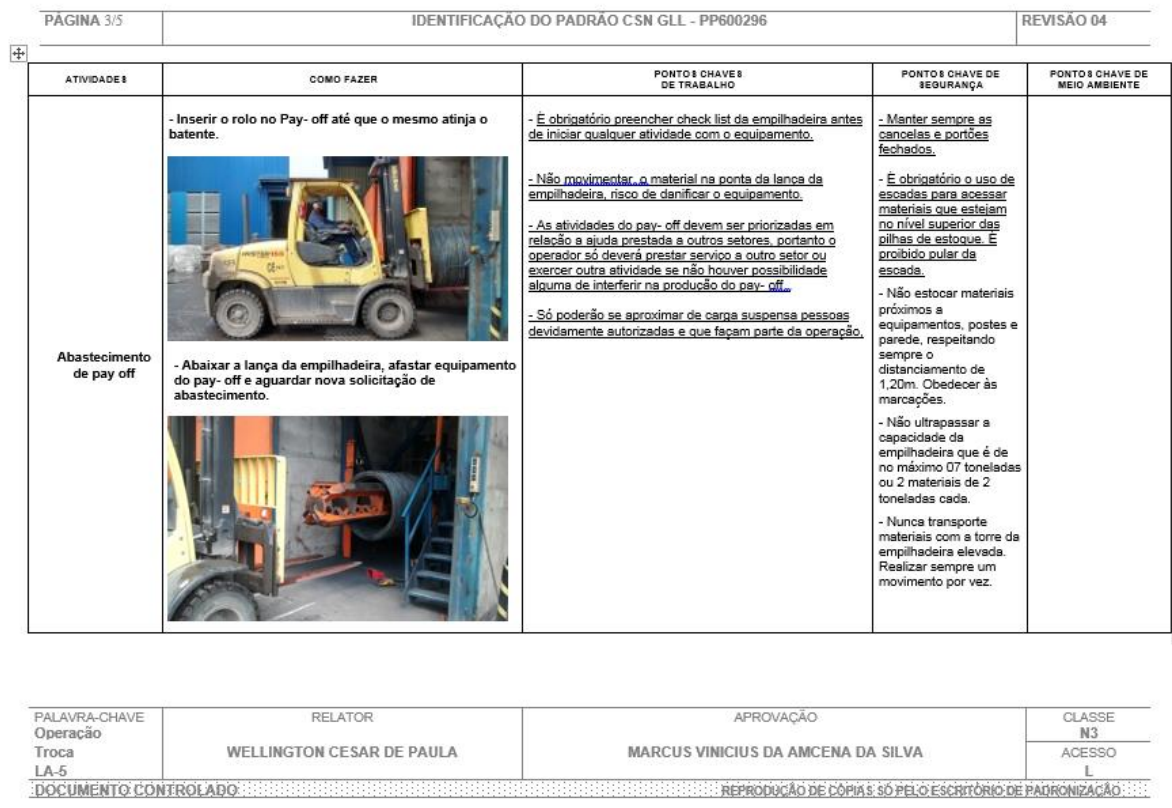

Figura 6. Modelo de procedimento 


\begin{tabular}{|l|c|}
\hline Evolução no no de procedimentos criados & $45 \%$ \\
\hline № de revisões realizadas & 37 \\
\hline № de treinamentos realizados & 1.550 \\
\hline
\end{tabular}

Tabela 1. Evolução dos procedimentos

A identificação de anomalias permite que seja sanado qualquer risco que possa gerar um acidente. Esses registros geram ações no local de trabalho e motivação ao colaborador. Permitindo que o mesmo tenha mais maturidade para apoiar ações relacionadas a segurança no seu próprio ambiente de trabalho. $O$ engajamento do mesmo traz uma contribuição intangível para empresa, que é a conscientização de si para a segurança. (Tabela 2)

\begin{tabular}{|l|c|}
\hline Total de no de relatos no período & 822 \\
\hline Evolução de relatos registrados no período & $222 \%$ \\
\hline Desvios sanados na área & $86 \%$ \\
\hline Abertura de projetos PDCA no tema & 2 \\
\hline
\end{tabular}

Tabela 2. Evolução dos relatos de anomalias

A análise dos riscos permite sinalizar cada tarefa de cada atividade classificando-a individualmente. Os casos mais críticos foram mitigados através de mudanças nas atividades, revisão do procedimento, novas sinalizações e compra de acessórios para os equipamentos. (Figura 7 )

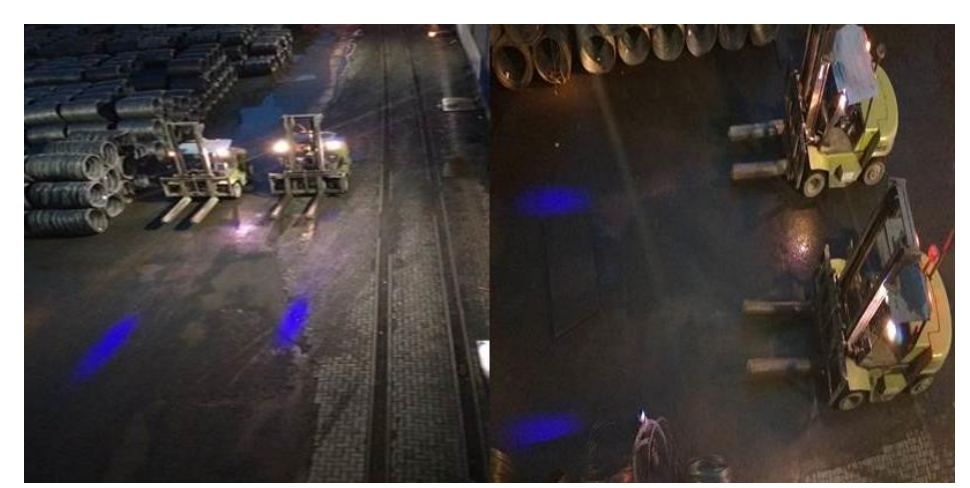

Figura 7. Instalação de acessório blue-spot nas empilhadeiras

Através dos registros das observações comportamentais realizadas na área foi possível identificar alguns erros ou desvios da própria equipe quando ao uso correto dos EPIs. Isso possibilitou intensificar treinamentos focados nesse tema e evidenciar dificuldades de entendimento e até mesmo de percepção da importância do uso dos equipamentos de proteção individual. (Figura 8) 


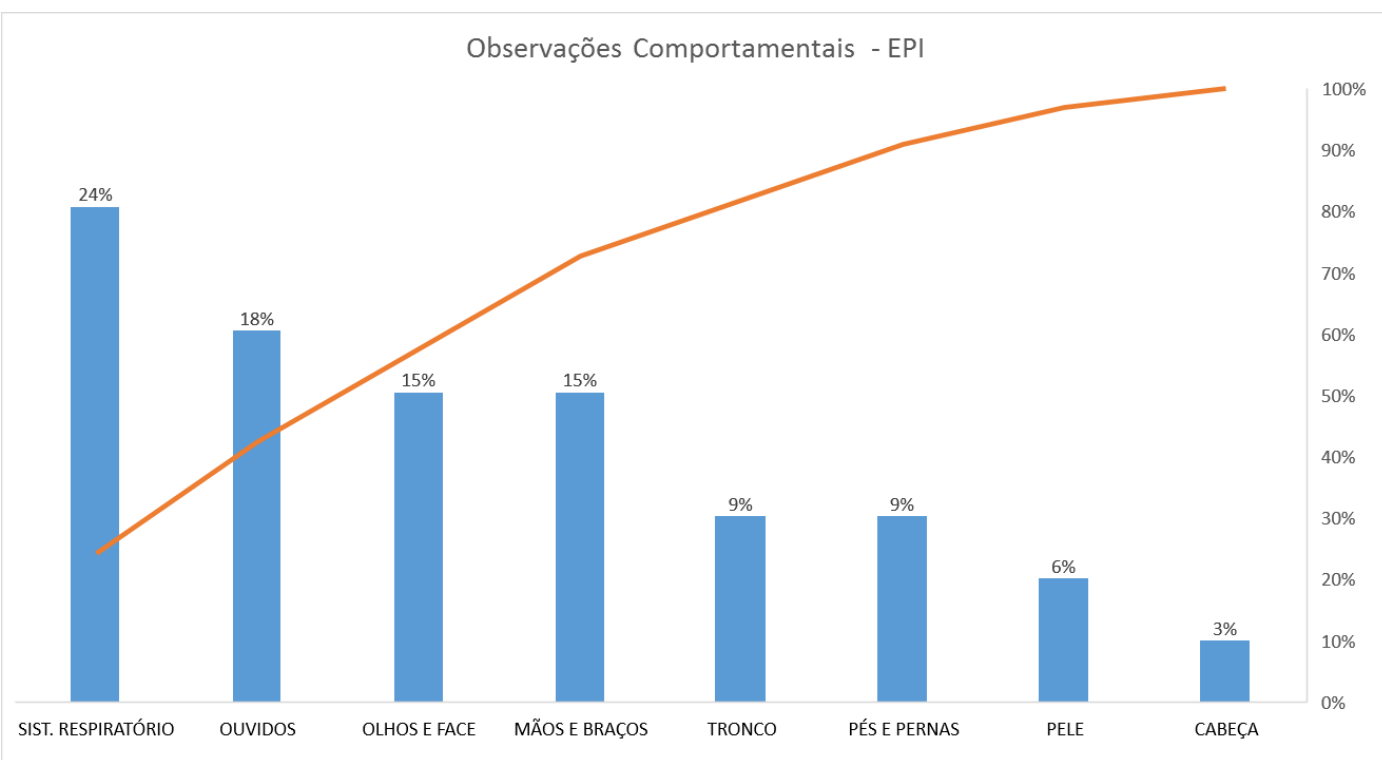

Figura 8. Análise da observação comportamental

A tratativa de todas as ferramentas e suas ações, bem como novas demandas de segurança, são abordadas e acompanhadas na reunião de segurança que ocorre sistematicamente com a equipe de Operacional, Supervisor, Gerente e Técnico de Segurança.

\section{CONCLUSÃO}

A implantação do sistema de gestão de segurança na área da Logística permitiu alcançar o número de 1.826 dias sem acidente com pessoas. OU seja, desde que a operação foi iniciada. É perceptível o desenvolvimento de toda a equipe no assunto segurança e a percepção do risco, que é inerente ao ambiente em que se atua.

Conforme a figura 9, a Curva de Bradley, ferramenta que auxilia e simplifica o trabalho no entendimento das mudanças de atitude e ação que devem ocorrer ao longo do tempo para desenvolver uma cultura de segurança madura nas empresas. Hoje podemos perceber que a maturidade está num nível satisfatório. Atualmente estamos em mudança no ponto de independência para a interdependência.

O resultado positivo está permitindo disseminar esse mesmo formato de gestão para outras áreas da empresa. 


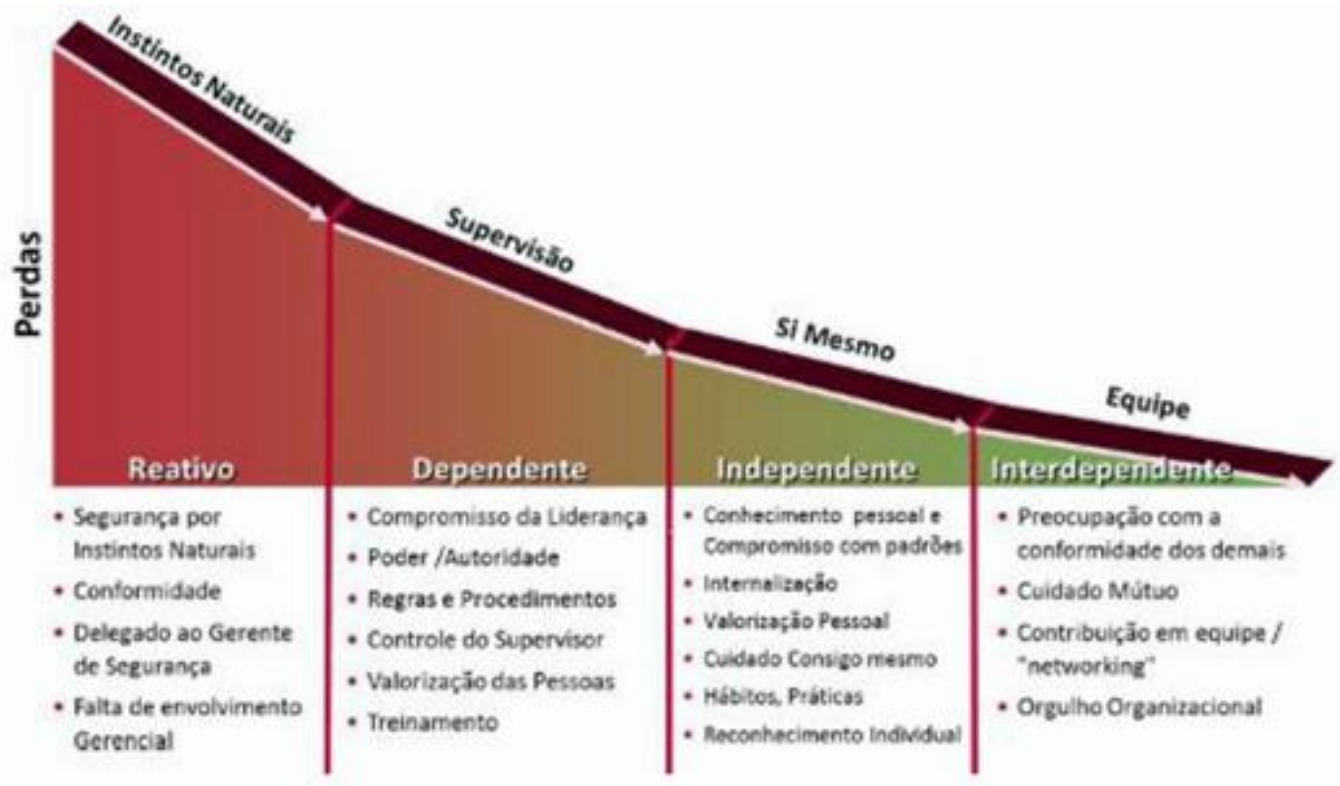

Figura 9. Evolução Cultural: Curva de Bradley

\section{REFERÊNCIAS}

1 DUPONT, Curva de Bradley da Dupont. Disponível em http://www.dupont.com.br/produtos-e-servicos/consulting-services-processtechnologies/segurancadotrabalho/usos-e-aplicacoes/bradley-curva.html

2 CAMPOS, D.C.; DIAS, M.C.F. A Cultura de Segurança no Trabalho: Um Estudo Exploratório.Niterói-RJ: Universidade Federal Fluminense, 2012

3 BLEY, Juliana Z. Comportamento Seguro. Belo Horizonte: Artesã, 2014.

4 FALCONI, C. V. Gerenciamento pelas diretrizes. Belo Horizonte: Fundação Christiano Ottoni, 1996. 